\title{
Living on the Edge: Against Epistemic Permissivism
}

\author{
Ginger Schultheis
}

September 22, 2016

To appear, Mind

\section{Introduction}

Matt and Abby are members of a jury for a murder case. They have all the same evidence and review it separately. When they convene to discuss their conclusions, they discover that they disagree. Matt is confident that Jones is innocent; Abby is confident that Jones is guilty. When they learn of their disagreement, what do they discover about themselves? Clearly, they learn that one of them is confident in a falsehood: Either Jones is guilty or he isn't. But do they also learn that one of them has been less than fully rational, that one has failed to properly assimilate the evidence before him?

Proponents of Epistemic Uniqueness say yes: Given your total evidence, there is a unique rational doxastic attitude that you can take to any proposition. ${ }^{1}$ Matt and Abby have the same evidence, but have different levels of confidence in the proposition that Jones is guilty (Guilty). Uniqueness entails that at most one of them is fully rational.

Proponents of Epistemic Permissivism say no. Matt and Abby may simply have different standards of reasoning. For example, Matt may tend to favor simple hypotheses, and Abby may tend to favor complex, more explanatory hypotheses. A permissivist thinks both standards of reasoning may be perfectly rational even though they sanction very different responses to the evidence. ${ }^{2}$

\footnotetext{
${ }^{1}$ This formulation is from White (2005).

${ }^{2}$ See Greco and Hedden (2015), Horowitz (2013), and White (2005) for arguments against versions of Epistemic Permissivism. See Ballantyne and Coffman (2012), Douven (2009), Kelly (2014), Kopec (2015), Meacham (2014), and Schoenfield (2014) for defenses. See Kopec and Titelbaum (2015) for an overview of various arguments for and against.
} 
Permissivists paint a simple, attractive picture of rationality. There are some general, justifiable rules - e.g., Conditionalization, Probabilism, and the Principal Principle - and a wide range of permissible starting points. So long as you begin at one of these, and you follow the rules, you're doing fine. Permissivists charge that Uniquers paint a much more complicated, and metaphysically loaded, picture of rationality. ${ }^{3}$ Uniquers must say everything Permissivists say, and much more - that there is a unique rational starting point, a unique rational credence in Guilty, and so forth.

I argue that Permissivists face a special challenge about the interaction between our firstand higher-order attitudes. They claim that rationality often permits a range of credences in a certain proposition. Yet given certain plausible assumptions about the relationship between our first- and higher-order attitudes, you cannot adopt a credence on the edge of that range. But Permissivism says that for some such range, any credence in that range is rational. So Permissivism is false. I consider new ways of developing Permissivism to avoid this argument, but they have problems of their own. ${ }^{4}$ Conclusion: Permissivism is not as simple as advertised, and without new motivations, it's not very attractive either.

On to the argument.

\section{Dominance}

Suppose that Permissivism is true and that Matt and Abby's evidence rationalizes any credence between, say, .3 and .7 in the proposition that Jones is guilty (Guilty). Quite plausibly, Matt is not always in a position to discern the exact boundaries of the permissible

\footnotetext{
${ }^{3}$ See e.g., Schoenfield (2014) and Kelly (2014) for this criticism.

${ }^{4}$ Strictly speaking, someone could be a Permissivist yet deny that there is ever a range of permissible credences in any proposition-you might think, say, that there are just two permissible credence in the proposition that Jones is guilty, .3 and .7. But the standard motivations - that there are some general, justifiable rules, and a wide range of starting points - strongly suggest that there will be a wide range of permissible credences in most propositions. If the Permissivist denies this, she owes us a general story about why there can never be such a range. Since no story like this has been told, I ignore this complication in this paper.
} 
range. ${ }^{5}$ Compare: He isn't able to determine the exact height of a tree some distance off just by looking - his eyesight is nowhere near that good. Similarly, by reflection alone, he can't reliably determine the value of the upper and lower bounds of the permissible range to the nearest (say) .01 degrees of confidence - the evidence is too complex, and his powers of reasoning are nowhere near that good. Even if he truly believes that the lower bound is .3 , he's merely guessing - for all he knows, the lower bound is .31 or .29. He can't reliably distinguish the actual case from one in which the lower bound is slightly higher or slightly lower.

Matt ought to know this about himself. He ought to know that if he were to guess the exact values of the upper and lower bound, he'd likely err. So, if the lower bound is .3, he shouldn't be certain that the lower bound is exactly .3. Compare: Since you know that you can't reliably guess the exact height of the tree some distance off, you shouldn't be certain that the tree is exactly 667 inches tall, even if it is - you should recognize that it might be slightly taller or slightly shorter. Similarly, Matt should acknowledge that the lower bound might well be slightly greater than .3 .

So what should Matt believe about the boundaries of the permissible range? That, it seems, depends on what they actually are. If the lower bound is actually .3, then he should believe that it is between (say) .2 and .4-that is, he should believe that it is roughly .3 . For even though rational requirements are not wholly transparent to us, they shouldn't be completely opaque to those who reflect carefully. After all, we regard careful reflection on our evidence as valuable precisely because it helps us form rational beliefs - beliefs that better reflect the force of our evidence. If the requirements of rationality were wholly inaccessible, what would justify such a practice?

So if Matt is rational, he believes that the permissible range of credences in Guilty spans from roughly .3 to roughly $.7 .^{6}$ But if he believes that, it would be irrational for him to

\footnotetext{
${ }^{5}$ See e.g., Christensen (2010), Elga (2013), Horowitz (2014), and Williamson (2000) for sympathetic discussion of similar claims.

${ }^{6}$ Note that this point is not specific to Permissivism. If Epistemic Uniqueness is true, and the unique
} 
adopt credence .3. Why? Because Matt is not certain that .3 is rational, but there are other credences whose rationality Matt does not doubt-he is certain that (say) .5 is rational. But when you are certain that a given credence is rational, it is irrational to adopt any other credence that you are not certain is rational: It is irrational to adopt credences that are, what I'll call, weakly rationality dominated.

A bit more precisely. Let an evidential situation be a complete specification of which credences are rational responses to one's evidence. Then where $c$ and $c^{\prime}$ are credences that a subject $\mathrm{S}$ might adopt,

Weak Rationality Dominance: $c$ weakly rationality dominates $c^{\prime}$ for $\mathrm{S}$ iff for every evidential situation that $\mathrm{S}$ treats as a live option and in which $c^{\prime}$ is rational, $c$ is too, and in some evidential situation that $\mathrm{S}$ treats as a live option, $c$ is rational, but $c^{\prime}$ is not.

Matt believes that the lower bound is roughly .3. To believe that the lower bound is roughly .3 is just to believe that it might be slightly higher or slightly lower than .3. Let's make a simplifying assumption that Matt treats three evidential situations as live options: that the lower bound is .2 , that it is .3 , and that it is .4. In each of these evidential situations in which it is rational to assign .3 to Guilty-i.e., when the lower bound is .2 or .3 - it is rational to assign .4 to Guilty. But in the evidential situation in which the lowest rational credence is .4, assigning .4 to Guilty is rational, and assigning .3 to Guilty is not. Hence, in some evidential situation that Matt treats as as a live option, assigning .4 to Guilty is rational, but assigning .3 to Guilty is not. So assigning .3 to Guilty is weakly rationality dominated by assigning .4 to Guilty for Matt.

But dominated options aren't rational: It's not rational to adopt a credence that's risky by your own lights when you know of a safer option. It follows that it is not rational for Matt

rational credence in Guilty is (say) .5, then Matt is not in a position to know that it is exactly .5, and so he too should believe that the rational credence is roughly .5. In my reply to the first objection, I'll show why this does not pose problems for the proponent of Uniqueness. Thanks to an anonymous referee for bringing this to my attention. 
to assign .3 to Guilty. But the Permissivist's hypothesis was that it's rationally permissible to adopt any credence between .3 and .7. We've now contradicted that assumption. Given what Matt ought to believe about the permissible range, it is irrational for Matt to adopt a credence on the edge of that range. ${ }^{7}$

The argument generalizes. For any range of putatively permissible credences in a proposition $\mathrm{P}$, it is irrational to assign to $\mathrm{P}$ the lowest (highest) value in that range - that is, it is irrational to adopt any credence on the edge of the permissible range. ${ }^{8}$ But Permissivism says that there is some range such that any credence in that range is permissible. Contradiction. $^{9}$

(Perhaps you wonder why we should care about rationality dominance: Our ultimate epistemic goal is not rationality per se but accuracy. Even if we grant this, we ought to recognize that epistemic rationality is a good guide to accuracy - in general, more rational credences are more accurate. On this view, we should avoid credences that are rationality dominated because we should do what we can to be most accurate. I return to this issue in my reply to Objection $5 .{ }^{10}$ )

In the remainder of the paper, I explore various objections to my argument and find them wanting. The upshot is that Permissivism faces a special challenge about the interaction between our first- and higher-order attitudes. Answering the challenge requires taking on

\footnotetext{
${ }^{7}$ I should note the dominance argument does not apply to an extreme version of Subjective Bayesianism that says that we are rationally required to follow the Bayesian formal constraints-probabilistic coherence and conditionalization - but there are no other constraints on what our priors should look like. Why? If any probabilistically coherent prior is permissible, the range of permissible credences in (almost) any proposition will be $[0,1]$ — any credence will be rationally permissible. And if that's right, we can be sure that our credences are rational, and so they won't be weakly rationality dominated. But for many, this extreme version of Subjective Bayesianism will seem too permissive. (It doesn't rule out counter-inductivists, for example.) My argument targets any moderate Permissivist - that is, any Permissivist who wants to carve out a space between (extreme) Subjective Bayesianism and Uniqueness.

${ }^{8} \mathrm{I}$ 'm simplifying here. If it is impermissible to take dominated options, then it will be irrational to adopt any credence that is close enough to the edge that you believe that it might fall just outside of the permissible range. This means that the argument goes through even if the range of permissible credences has no lowest or highest value.

${ }^{9}$ The Permissivist might object that I oversell the force of the dominance argument. If the range of permissible credences in Guilty is narrow, so narrow that Matt is not certain that any particular credence is rational, then his .3 credence in Guilty will not be rationality dominated. Granted. But the Permissivist shouldn't rest content. For the guiding motivations for Epistemic Permissivism - e.g., that different people can rationally come to opposite conclusions about an issue - strongly suggest that the permissible range of credences will often be very wide. See Rosen (2001) and Schoenfield (2014).

${ }^{10}$ Thanks to an anonymous referee for bringing this to my attention.
} 
new, unattractive commitments about how we form higher-order beliefs or about what it is permissible to do in the face of higher-order uncertainty. Perhaps we will conclude in the end that those commitments are worth carrying to save Permissivism. But if we do accept Permissivism, we should do so with clear eyes. We should know what burdens we shoulder.

\section{Objections and Replies}

Objection 1: Your argument exploits the vagueness of epistemic permissibility. It relies on the premise that if a certain credence is not rational, then no credence sufficiently close to it is rational, either. But any premise of that form is soritical, and so ought to be rejected.

Reply: That premise is indeed soritical, but my argument doesn't rely on it. I do not say that since .3 is irrational, so too is .31 . If my argument did rely on this premise, it would have the (absurd) consequence that there are no rational credences. But it has no such consequence.

To see this, take the limiting case, where there is just one permissible credence in Guilty - say, .5. If .5 is the unique rational credence in Guilty, then Matt ought to believe that it is roughly .5 (reflection doesn't get us all the way to the truth, but it gets us somewhere). Now, if Matt believes that the rational credence is roughly .5, then if he assigns .5 to Guilty, he won't be certain that his own credence is rational. But that's not itself irrational: Although Matt is not certain that his credence is rational, he is not certain, of any particular credence, that it is rational. There is no other credence Matt thinks would be better than his own. ${ }^{11}$ When the rationality of everything is in doubt,

\footnotetext{
${ }^{11}$ Christensen (2010) gives an example of what seems to be a fully rational agent who is uncertain about what the rational credence is. Ava is considering the possibility that the next US President will be a Democrat (D). On page 121, Christensen says, 'Ava gives D some particular crednece, say, .7; this reflects a great deal of her general knowledge, her feel for public opinion, her knowledge of possible candidates, etc. But given the possibility that her credence is affected by wishful thinking, protective pessimism, or just failure to focus on and perfectly integrate an unruly mass of evidence, Ava very much doubts that her credence is exactly what her evidence supports. This seems only natural; indeed, eminently reasonable.'
} 
assigning .5 credence to Guilty will not be rationality dominated for Matt. Like clear-eyed Permissivists, clear-eyed Uniquers are uncertain about the rationality of their credences; unlike clear-eyed Permissivists, they are not sure that any other credences are rational. (By 'clear-eyed Permissivist', I mean someone who believes, of a certain case, that it is a permissive one. By 'clear-eyed Uniquer', I mean someone who believes that there are no permissive cases.)

The dominance argument works against Permissivism because if there is a wide range of credences, Matt can be sure that certain credences in the middle of the range are rationalbeing in the middle will be safer, by Matt's lights, than being on the edge. But if you think there's just one rational credence, nothing will be perfectly safe by your lights. Matt may assign .5 credence to Guilty because this credence will not be rationality dominated by any other credence.

Objection 2: Ideally rational agents know exactly what rationality permits. So, in particular, if Matt is ideally rational, he is certain that the permissible range of credences in Guilty spans from exactly .3 to exactly .7, and so he is no victim of the dominance argument.

Reply: Maybe. ${ }^{12}$ But Epistemic Permissivism is not just a view about ideally rational agents, but about ordinary agents like you and me, with all our human limitations. Indeed, Permissivists often tout their view as the only alternative to an objectionably demanding epistemology. Try to imagine yourself in Matt's shoes, they say. You're faced with a mess of evidence. Jones' glove was found on the scene, but another suspect's fingerprints were there too. Three witnesses claim that Jones owned a gun and was prone to violence. Two others

\footnotetext{
${ }^{12}$ Why 'maybe'? Because it isn't clear that even ideally rational agents are certain about which credences are licensed by their evidence. Here's one reason to think they aren't. Ideally rational agents aren't always in a position to know exactly what they know. In particular, knowledge does not obey negative introspection: Ideally rational agents can fail to know $P$ without also knowing that they don't know $P$. But if we accept, following Williamson (2000), that our evidence just is our knowledge, then even ideally rational agents won't know exactly what their evidence is - sometimes they will be rationally uncertain about which credences are rational.
} 
deny this. And so on. Could it really be that the only rational response to his evidence is for Matt to become (say) .6453 confident in Guilty? Surely not, the Permissivist says. Rationality does not require us to do the impossible - typically there is a wide range of responses to our evidence that would be rational. ${ }^{13}$

If the Permissivist embraces this motivation, then surely when she says that it is permissible to hold any credence between .3 and .7 , she means that it is permissible for someone like Matt - a non-ideal, cognitively limited agent — to hold any credence between .3 and .7. But I've argued that this can't be. A non-ideal agent ought not to be certain of the exact boundaries of the permissible range, so he cannot adopt a credence on the edge of that range.

But even if the Permissivist eschews this motivation, I don't think she's much better off. To be sure, the dominance argument does not apply to those who are certain of the exact boundaries of the permissible range. So, for any credence between .3 and .7 in Guilty, perhaps there is an ideally rational agent who holds that credence. But the argument still applies to ordinary agents - their options will be much more constrained. This leaves us with quite a surprising account of rationality, one that affords ideally rational agents many, many options, and limits ordinary agents to just one.

This is exactly the opposite of what we should expect from a Permissivist who recognizes a distinction between ideal and non-ideal rationality. Permissivism is populist epistemology, a view for ordinary folk. Impermissivists ignore the realities of our actual cognitive lives. Permissivists don't. If the Permissivist grants that any form of rationality is impermissive, it should be an idealized notion, one that abstracts away from our actual cognitive limitations, and so, by their lights, has little relevance for people like us. Absent a suitable story about why things would be reversed - why it would be ideal rationality that is permissive and non-ideal rationality that is impermissive - we should be suspicious of an appeal to ideal

\footnotetext{
${ }^{13}$ See e.g., Schoenfield (2014) for arguments like this.
} 
rationality as a way of evading the dominance argument.

Objection 3: Matt should believe that he is in the middle of the permissible range. Suppose we grant that it is impermissible to adopt dominated options. Then we must say that, if he believes that the boundary of the permissible range is roughly .3, it is irrational for Matt to be .3 confident in Guilty. Matt shouldn't regard himself as taking an unnecessary risk. But that doesn't mean the .3 credence has to go, as I've argued. Rather, it's Matt's higher-order beliefs that should change: Matt should believe that his .3 credence is close to the middle of the range of permissible credences in Guilty, so that he is certain that . 3 is rational.

Reply: If you take this strategy, you need a story about how we form higher-order beliefs that explains why agents on the edge of the permissible range must always believe falsely that they are (roughly) in the middle. To be sure, agents can form false beliefs about what rationality permits if they have misleading higher-order evidence. Matt may get misleading higher-order evidence suggesting that the permissible range of credences in Guilty spans from roughly .1 to roughly .5. I don't doubt that it would then be permissible for him to assign .3 to Guilty. But Epistemic Permissivism is not just a view about what we are permitted to believe when we are misled. We need an account of how we form higher-order beliefs that explains how it can be rational for agents on the edge to believe falsely that they are in the middle, even in the absence of misleading higher-order evidence.

The kind of story about higher-order belief formation that we are interested in is one that tells Matt and Abby to believe that they are in the middle of the permissible range. So, since Matt assigns .3 to Guilty, he ought to believe that the range of permissible credences in Guilty is roughly .1-.5, and since Abby assigns .7 to Guilty, she ought to believe that the range of permissible credences is roughly .5-.9. What kind of method must Matt and Abby be using to form these higher-order beliefs? It must be one that takes into account their own credences in Guilty. 
Perhaps the story goes like this. In general, you are rationally entitled to believe that your own credences and beliefs are rational. So, when Matt examines the evidence and adopts . 3 , he is thereby permitted to infer that .3 is rational. Similarly, when Abby examines the evidence and adopts .7 credence, she is thereby permitted to believe that .7 is rational. Now, the story can't stop there, for since Matt and Abby are clear-eyed Permissivists, they think other credences are rational, too. Which ones? A natural thought: Those that are sufficiently close to their own! Matt reasons, 'I know that .3 is rational. So any credence as low as .1 or as high as .5 is probably rational, too', and Abby reasons, 'I know that .7 is rational, so anything as low as .5 and as high as .9 is rational, too.' Can this procedure explain how Matt and Abby could rationally believe that they are in the middle of the range?

I think not. For if your credence is sufficiently close to the edge, this procedure will lead you astray about the upper and lower bounds of the permissible range, as it does for Matt and Abby. Now, the unreliability of the method is not itself the problem-perhaps we are sometimes rational to use unreliable methods. What's worrying is that a clear-eyed Permissivist is in a position to know that the method is unreliable.

To see why, it will be instructive to compare Permissivism to Uniqueness on this issue. Suppose that I am a clear-eyed Uniquer. In that case, I know that, if my first-order belief or credence is rational, then if I come to believe that my own credence is rational, my belief will be true. In short, if Uniqueness is true, then the rational entitlement principle guarantees that rational agents will form true beliefs about rationality, and clear-eyed Uniquers are in a position to rationally believe this about themselves.

Things are different for Permissivism. Matt is a clear-eyed Permissivist. He believes that his credence in Guilty is rational and infers that all credences close to his are rational. That's how Matt comes to believe that the range of permissible credences in Guilty is roughly .1 to roughly .5. But although being rational guarantees that you will form true 
beliefs about the rationality of your own credence, it does not guarantee that you will form true beliefs about the upper and lower bounds of the permissible range of credences - it doesn't guarantee that you will form true beliefs about what other credences are rational.

But Matt in a position to know this about the method he is using. Matt should be highly confident that he is on the edge of the permissible range of credences in some propositions, and for all he knows, Guilty is one of them. So, Matt should recognize that, for all he knows, his credence is on the edge of the range of permissible credences in Guilty. Matt should doubt the conclusion of the method he is using: He should think, 'Even if my credence in Guilty is rational, I might be on the edge of the permissible range, in which case my belief that all credences close to my own are rational will be false!' But it can't be rational to use a method whose conclusions one doubts. If I am in a position to know a priori that a conclusion I've drawn might be false, I shouldn't believe it. Pending a suitable story about higher-order belief formation, we ought to be suspicious of a view that says that we must always believe that our credences are close to the middle of the permissible range.

Objection 4: You assume that if Permissivism is true, then Matt can rationally believe he is in a permissive case. But some Permissivists deny this. For example, Stewart Cohen (2013) is a Permissivist who defends Doxastic Uniqueness, the claim that a subject cannot rationally hold one credence while believing that some other credence is just as rational. That is, a subject can never rationally believe that she is in a permissive case. If Matt doesn't believe that there is a range of permissible credences in Guilty, the threat of dominance evaporates.

Reply: Granted. But the traditional motivations for Permissivism strongly suggest that if Permissivism is true, then we can, at least sometimes, rationally believe that we are in a permissive case. ${ }^{14}$

\footnotetext{
${ }^{14}$ See Ballantyne and Coffman (2011), Douven (2009), Kelly (2013), Schoenfield (2014), and Titelbaum and Kopec (2015) for defenses of clear-eyed Permissivism, the view that Permissivism true and we're
} 
Permissivist usually motivate their view, at least in part, by reflection on particular cases - cases of disagreement among jurors about whether Jones is guilty, among paleontologists about what killed off the dinosaurs, and among philosophers about whether we have free will. But if we can know that a particular case is permissive when we're doing epistemology, what could stop us from continuing to know that a particular case is permissive when we're in one?

A second way of motivating Permissivism, the 'competing theoretical virtues' argument, also suggests that we often know that we're in a permissive case. Permissivists say that what it's rational for us to believe depends not just on the content of our evidence, but on how we balance certain theoretical virtues against each other-things like simplicity, predictive strength, and explanatory power. There are many different, yet equally rational ways of balancing these virtues against one another, and they will often yield different levels of confidence in various hypotheses. ${ }^{15}$

But surely we can tell, at least sometimes, how simple, predictive, and explanatory a certain hypothesis is. If we can, then we can also determine, say, that balancing simplicity and predictive power in this way would yield high credence in Guilty, and weighing them in that way would yield lower credence in Guilty. But if we also know that both of these ways of balancing the theoretical virtues are rational, we can put two and two together, and conclude that high credence and low credence in Guilty are both rational. ${ }^{16}$

Objection 5: It can be permissible for Matt to hold onto a credence that is rationality dominated. Matt's credence has something else going for it: He expects it to be most accurate. Why? Because Matt's credence is recommended by his own epistemic standards, which he endorses: Matt expects the credences recommended by his standards to be more accurate than those recommended by any other standards.

sometimes in a position to know, of a certain case, that it is permissive.

${ }^{15}$ See, for example, Douven (2009), Schoenfield (2014), and Titelbaum (2015a) for arguments along these lines.

${ }^{16}$ Thanks to an anonymous referee for suggesting this point. 
This argument is not new: It's Schoenfield's (2014) response to White's (2005) charge that if Permissivism is true, then it should be fine to arbitrarily switch from one permissible credence to another. ${ }^{17}$ We can think of Schoenfield's brand of Permissivism as a kind of Intrapersonal Epistemic Uniqueness: There are many, equally permissible sets of epistemic standards, but once you've settled on one, you have reason to adopt the credences your standards recommend. (For Schoenfield, that's because if you're rational, you expect your standards to maximize expected accuracy.) ${ }^{18}$ So, contra White, it is never rational to arbitrarily switch from one permissible credence to another.

If we're convinced by Schoenfield's reply to White's, might we use it to reply to my challenge as well?

Reply: There are two ways of understanding Schoenfield's reply on behalf of the Intrapersonal Epistemic Uniquer, one weaker, one stronger: the weaker, though plausibly an effective response to White's challenge, is no objection to mine; the stronger is indeed an objection to the dominance principle, but, intuitively, it is far too strong. ${ }^{19}$

The weaker version of Schoenfield's reply says that expecting some credence to be most accurate is sometimes a reason to prefer it - in particular, it is a reason to prefer it when the rationality of the various credences you're considering is not in doubt. This is the thought that in fact motivates Schoenfield's reply to White above (see footnote 21). Plausibly, Schoenfield has answered White's challenge - she has explained why, when you know that some other credence is just as rational as yours, you still have reason to prefer your own.

But the weaker version of Schoenfield's reply does not help the Permissivist answer my challenge - she does not (nor does she intend to) explain why it would be permissible to hold onto credences that are rationality dominated. After all, cases in which your credence

\footnotetext{
${ }^{17}$ White presents many arguments against Permissivism, but I take this to be the central objection unifying all of them.

${ }^{18}$ Kelly (2014), Meacham (2014), and Titelbaum and Kopec (2015) also defend Intrapersonal Uniqueness, and discuss how this view helps us respond to White.

${ }^{19}$ Thanks to Bernhard Salow for discussion on the arguments of this section.
} 
is rationality dominated are precisely those cases in which the rationality of one of the credences you are considering is in doubt.

The stronger version of Schoenfield's reply says that expecting your credence to be most accurate is always a reason to prefer it - in particular, it is a reason to prefer it even when the rationality of that credence is in doubt. This is is indeed an objection to the dominance principle, the principle that it is always irrational to adopt weakly dominated credences. The stronger version of Schoenfield's reply says that you should stick to your credence when it is rationality dominated because you expect it to be most accurate.

But it's not an objection the Permissivist should be happy to pursue. It implies that we should never be moved to revise our credences by evidence that we've been less than fully rational; instead we should level-split-e.g., we should both remain highly confident that Jones is not guilty and believe that our evidence supports lower confidence in this proposition. This is not a welcome consequence. Those who refuse to revise their beliefs in the face of evidence that they are irrational seem over-confident, indeed dogmatic - they seem paradigmatically irrational.

Suppose Jill has examined all of the evidence and becomes highly confident that the Warriors, her favorite NBA team, will win the championship. A trusted friend tells her that she always overestimates the likelihood of favorable outcomes. The Permissivist we're considering says that Jill should remain highly confident that the Warriors will win despite her friend's warning. Since she expects her high credence to be most accurate, she needn't be worried by evidence that she's been irrational.

This doesn't seem right. When she has reason to believe her credence is irrational, Jill shouldn't be able to appeal to the perceived accuracy of her credence as a reason to hold onto it. Compare this to a case of all-out beliefs. Suppose that Jill simply believes that the Warriors will win, and her friend tells that the evidence doesn't support such high confidence. Jill couldn't reply to her friend's concern: 'Well, I must have gotten lucky —even 
though the evidence supports lower confidence, I've wound up with a true belief!'20 Return to the case of credences. Jill can't respond to her friend's concern about the rationality of her credence with: 'Well, I must have gotten lucky — even though my evidence supports a lower credence, my credence is more accurate!' Evidence that she has been irrational should make her doubt the accuracy of her credences and beliefs, and she should lower her confidence accordingly.

Similar things can be said of Matt's credence in Guilty. He worries that his credence might be too low. But he's sure that it's not too high- - he's certain that it would be rational to assign .4 to Guilty. The Permissivist we're considering says that he needn't be moved by doubts about the rationality of his .3 credence in Guilty because he expects it to be most accurate. But again, this seems wrong. Matt cannot appeal to the perceived accuracy of his credence as a reason to maintain that credence when its rationality is in doubt. ${ }^{21}$

This is connected to a worry I mentioned earlier: Don’t rational agents care rationality only as a guide to accuracy, and not for its own sake? If so, accuracy always comes first. But then my dominance principle is false: Because he expects his credence to be more accurate than any other credence, Matt should stick with .3 even if he isn't sure it is rational and he is sure that (say) .4 is rational. To shift from .3 to .4 in order to ensure rationality - at the cost of accuracy by Matt's lights-would be irrational.

But I deny that it can be rational for Matt to expect his credence to be most accurate when he has reason to believe that his credence might be irrational, and he is sure that some other credence is rational. If Matt were sure that his credence is rational, then perhaps

\footnotetext{
${ }^{20}$ For defenses or sympathetic discussion of the claim that it is irrational to maintain some credence or belief when you acquire evidence that it is irrational, see Christensen (2010), Elga (2013), Greco (2014), Horowitz (2014), Sliwa and Horowitz (2015), Smithies (2012), and Titelbaum (2015b). For criticism see Coates (2012), Lasonen-Aarnio (2014), Lasonen-Aarnio (2015), and Williamson (2011).

${ }^{21}$ It is Schoenfield's discussion of irrelevant influences on belief that makes explicit that she endorses only the weaker version of Intrapersonal Uniqueness. She's interested in cases where you learn that your belief was influenced by an irrelevant factor. In cases like this, it seems we should revise our earlier beliefs. Schoenfield explains this intuition by saying that we should revise our beliefs when we have reason to believe that they are irrational. (See pages 203-206.) Schoenfield accepts that if you have evidence that you've picked standards in a way that was unlikely to leave you with rational ones, then you ought to change them. It's a short step from this thought to my dominance principle.
} 
it would be rational for him to expect it to be most accurate. But the moment he starts doubting the rationality of his credence, continuing to assume that it is most accurate seems overly self-confident and dogmatic.

Even if we don't care about rationality for its own sake, it is a good guide to accuracyin general, more rational credences are more accurate than less rational ones. But then we ought to see it that way - if we expect one credence to be more rational than another, we should also expect it to be more accurate, and so we should prefer it. Since Matt expects .4 to be more rational than .3-he's sure that .4 is rational but he is not sure that .3 is - he should also expect .4 to be more accurate than .3, and Matt should revise his credence accordingly. On this view, avoiding dominated credences is just part of doing what we can to be most accurate.

Let's take a step back. As we've seen, I'm not the first to object to Permissivism. White argued that if you know that you're in a permissive case, then it is okay to arbitrarily switch credences. As we saw in Objection 4, some Permissivists simply deny that we ever know that we are in a permissive case, and such Permissivists escape my dominance argument.

But the Permissivists who endorse the traditional motivations for the view-e.g., competing theoretical virtues - say that you can know that you are in a permissive case, but it is nonetheless not okay to arbitrarily switch. These Permissivists must say that rational agents have some to reason privilege their own credences even when they know that some other credence is just as rational. Perhaps that reason is that the standards of a rational agent maximize expected accuracy for that agent, as Schoenfield argues. Or perhaps it's simply that we should be (diachronically) consistent; we shouldn't change our minds arbitrarily. $^{22}$

But whatever the reason is, we must ask the question that I asked in response to Schoen-

\footnotetext{
${ }^{22}$ See Titelbaum and Kopec (2015) for a discussion of how appealing to certain norms of diachronic consistency helps us reply to White.
} 
field: What is the force of the reason? Do we always have reason to adopt the credences that our standards recommend? Or rather, can it be defeated by evidence that our credences (and so our standards, too) are irrational? As we've seen, the Permissivist should accept that if you have reason to believe that your standards are irrational, then whatever reason you had to adhere to your standards is defeated - when the rationality of a certain credence is in doubt, that it is recommended by your standards is no reason to prefer it.

It is a far cry from the thought that you shouldn't change your mind arbitrarily to the thought that you shouldn't change your mind even when you have reason to believe that your present attitude is irrational. But I have argued that this is the predicament of the clear-eyed Permissivist on the edge of the permissible range. It's not that he believes that some other credence is just as rational as his. No, it's that he expects some other credence to be more rational than his. (Matt is sure that .5 is rational but he is not sure that .3 is rational.) To privilege your credence when the rationality of that credence is not in doubt is one thing; to do so when you have reason to believe it might be irrational, and you're sure that some other credence is rational, is quite another.

The dominance argument goes through so long as you admit that it is rational to revise your credences when you're not sure that your credence is rational but you are sure that some other credence is rational. And any Permissivist should admit this much.

\section{Conclusion}

I've argued that if you are on the edge of the permissible range of credences in a certain proposition, your credence will be rationality dominated by certain credences closer to the middle. Since dominated options aren't rational, it's not rational to adopt a credence on the edge of the permissible range. But Permissivism says that, for some such range, any

credence in that range is rationally permissible. I have considered some objections to my 
argument and found them wanting. Permissivism, in its traditional form, cannot be right. ${ }^{23}$

\section{References}

[1] Ballantyne, Nathan and Coffman, E.J. 2012, 'Conciliationism and Uniqueness'. Australasian Journal of Philosophy, 90, pp. 657-70.

[2] Christensen, David 2010, 'Rational Reflection'. Philosophical Perspectives, 24, pp. $121-40$.

[3] Christensen, David and Lackey, Jennifer (eds.) 2013, The Epistemology of Disagreement: New Essays, Oxford: Oxford University Press.

[4] Coates, Allen 2012, 'Rational Epistemic Akrasia'. American Philosophical Quarterly, 49, pp. $113-24$.

[5] Cohen, Stewart 2013, 'A Defense of the Almost Equal Weight View'. In Christensen and Lackey, 2013, pp. 98-119.

[6] Dougherty, Trent (ed.) 2011, Evidentialism and its Discontents. Oxford: Oxford University Press.

[7] Douven, Igor. 2009, 'Uniqueness Revisited'. American Philosophical Quarterly, 46, pp. 347-61.

[8] Elga, Adam. 2013, 'The Puzzle of the Unmarked Clock and the New Rational Reflection Principle'. Philosophical Studies. 164, pp. 98-120.

[9] Greco, Daniel 2014, 'A Puzzle about Epistemic Akrasia'. Philosophical Studies. 167, pp. 201-19.

\footnotetext{
${ }^{23}$ Thanks to David Boylan, Alex Byrne, Cosmo Grant, Matt Mandelkern, Dan Greco, Sophie Horowitz, Miriam Schoenfield, Kieran Setiya, Jack Spencer, Roger White, and, especially, Kevin Dorst, Milo PhillipsBrown, and Bernhard Salow for many helpful discussions.
} 
[10] Greco, Daniel and Hedden, Brian 2015, 'Uniqueness and Metaepistemology'. forthcoming in The Journal of Philosophy.

[11] Horowitz, Sophie 2013, 'Immoderately Rational'. Philosophical Studies, 167, pp. 1-16.

[12] — 2014, 'Epistemic Akrasia'. Noûs, 48, pp. 718-44.

[13] Kopec, Matthew 2015, 'A Counterexample to the Uniqueness Thesis'. Philosophia, 43, pp. 403-09.

[14] Kopec, Matthew and Titelbaum, Michael G. 2015, 'The Uniqueness Thesis'. forthcoming in The Philosophical Compass.

[15] Lasonen-Aarnio, Maria 2014, 'Higher-order Evidence and the Limits of Defeat'. Philosophy and Phenomenological Research, 88, pp. 314-45.

[16] — 2015: 'New Rational Reflection and Internalism about Rationality'. In Hawthorne and Gendler 2015, pp. 145-71.

[17] Meacham, Christopher J.G. 2014, 'Impermissive Bayesianism'. Erkenntnis, 79, pp. $1185-1217$.

[18] Rosen, Gideon 2001, 'Nominalism, Naturalism, and Epistemic Relativism'. Philosophical Perspectives, 15, pp. 69-91.

[19] Schoenfield, Miriam 2014, 'Permission to Believe: Why Permissivism is True and what it Tells us about Irrelevant Influences on Belief'. Noûs, 48, 198-218.

[20] Sliwa, Paulina and Horowitz, Sophie 2015, 'Respecting all the Evidence'. Philosophical Studies, 172, 2835-2858.

[21] Smithies, Declan 2012, 'Moore's Paradox and the Accessibility of Justification'. Philosophy and Phenomenological Research, 85, pp. 273-300. 
[22] Szabó Gendler, Tamar and Hawthorne, John (eds.) 2015, Oxford Studies in Epistemology, volume 5. Oxford: Oxford University Press.

[23] Titelbaum, Michael G. 2010, 'Not Enough There There: Evidence, Reasons, and Language Independence'. Philosophical Perspectives, 24, pp. 477-528.

[24] — 2015a: 'Continuing On'. Canadian Journal of Philosophy, 45, pp. 670-691.

[25] — 2015b: 'Rationality's Fixed Point (or: In Defense of Right Reason)'. In Gendler and Hawthorne 2015, pp. 253-294.

[26] White, Roger 2005, 'Epistemic Permissiveness'. Philosophical Perspectives, 19, pp. 445-459.

[27] Williamson, Timothy 2000, Knowledge and its Limits. Oxford: Oxford University Press.

[28] 2011: 'Improbable Knowing'. In Trent Dougherty, 2011, pp. 149-64. 